\title{
Posterior Fossa Teratomas in Adults : A Systematic Review
}

\author{
Dong-Won Shin, Jeong Hoon Kim, Sang Woo Song, ${ }^{1}$ Young-Hoon Kim, ${ }^{1}$ Young Hyun Cho, ${ }^{1}$ Seok Ho Hong, Soo Jeong Nam ${ }^{2}$ \\ Department of Neurosurgery,' Asan Medical Center, College of Medicine, University of Ulsan, Seoul, Korea \\ Department of Pathology, ${ }^{2}$ Asan Medical Center, College of Medicine, University of Ulsan, Seoul, Korea
}

Objective : The occurrence of posterior fossa teratomas in adulthood is extremely rare. In this study, we aimed to report our experience with two cases of posterior fossa mature teratoma in adults who underwent surgical resection. We also performed a systematic review of published papers available to date.

Methods : We retrospectively reviewed the electronic medical records of patients who had onset of posterior fossa teratomas in adulthood at our institute between 1995 and 2020. We evaluated the clinical, radiographic, and pathological features of mature teratomas at the posterior fossa in adulthood. Furthermore, we searched the PubMed, EMBASE, and Web of Science database and reviewed published articles.

Results : We found 507 articles on database review; of them, 102 were duplicates and 389 were excluded based on the inclusion criteria. Finally, 16 cases of posterior fossa from the web search and related articles. Subsequently, we added two cases that underwent surgery at our institute. We analyzed a total of 18 cases of mature teratomas. Headache was the most common (55.6\%) symptom. The teratomas showed heterogeneous signals on magnetic resonance imaging. Thirteen patients (72.2\%) had lesion at midline, five patients (27.8\%) had calcification. Surgical resection was performed in all patients. No studies reported recurrence after resection.

Conclusion : The occurrence of posterior fossa teratomas in adulthood is difficult to diagnose at the initial stage. Radiographic diagnosis alone can lead to misdiagnosis. Pathological confirmation is essential. Surgical resection is a curative option for posterior fossa teratomas in adulthood.

Key Words : Teratoma · Neoplasms · Cerebellum · Brain stem.

\section{INTRODUCTION}

Teratomas account for $0.1-1.5 \%$ of all intracranial tumors and $2-4 \%$ of all intracranial tumors in children ${ }^{3,7,920}$. They usually occur near the midline and demonstrate two peaks by age distribution — during the neonatal/infancy period and between the age of $5-14$ years $^{3,11,15)}$. They frequently occupy the pineal region $(51 \%)$, followed by the sellar area $(30 \%)^{3)}$. The occurrence of posterior fossa teratomas in adulthood is extremely rare. Only several cases have been reported thus far in the literature $\mathrm{1}^{1,3-8,10,13,16,18-24)}$. The prognosis and clinical, histological, and radiographic features of posterior fossa teratomas are unknown. This study aimed to present our experience of posterior fossa mature teratoma in adults who underwent surgical resection at our institute. Furthermore, we performed a systematic literature review reporting all cases of posterior

- Received : December 8, 2020 •Revised : January 22, 2021 •Accepted : February 9, 2021

- Address for reprints : Jeong Hoon Kim

Department of Neurosurgery, Asan Medical Center, College of Medicine, University of Ulsan, 88 Olympic-ro 43-gil, Songpa-gu, Seoul 05505, Korea Tel : +82-2-3010-3550, Fax : +82-2-476-6738, E-mail : jhkim1@amc.seoul.kr, ORCID : https://orcid.org/0000-0001-7385-2368

This is an Open Access article distributed under the terms of the Creative Commons Attribution Non-Commercial License (http://creativecommons.org/licenses/by-nc/4.0) which permits unrestricted non-commercial use, distribution, and reproduction in any medium, provided the original work is properly cited. 
fossa mature teratoma that occurred in adulthood published thus far and described their peculiar features.

\section{MATERIALS AND METHODS}

All procedures performed in studies involving human participants were in accordance with the ethical standards of the Institutional Research Committee (Asan Medical Center, reference No. 2020-1568) and with the 1964 Helsinki declaration and its later amendments or comparable ethical standards.

\section{Search strategy}

Our study follows Preferred Reporting Items for Systematic Reviews and Meta-Analyses guideline. Using the PubMed, EMBASE, and Web of Science. We conducted a systematic review of the literature and searched for reported cases of posterior fossa teratoma in adult patients in articles published up to 2020. We searched the database using a combination of the following terms : "mature teratoma in posterior fossa," "cerebellum mature teratoma," and "adult posterior fossa teratoma." Only studies published in English were considered. Additional relevant studies were manually searched by reviewing the reference lists of identified studies and using the "related articles" tool in PubMed. Unpublished data or congress presentations as well as autopsy cases were not considered.

\section{Study selection}

Articles were eligible for inclusion if the diagnosis of mature teratoma in the posterior fossa had been confirmed histologically. Pediatric studies were excluded.

\section{Data abstraction}

The selected articles were analyzed for clinical presentation, radiologic features, final diagnosis, and clinical outcome. The corresponding authors of each article were contacted by e-mail to obtain more detailed information regarding follow-up and complementary treatment. We also reported mature teratoma in the posterior fossa from our neurosurgical department.

\section{RESULTS}

Fig. 1 shows a flow chart of the literature review process. A total of 502 articles were shortlisted in the search. An additional five related articles were identified through a search of

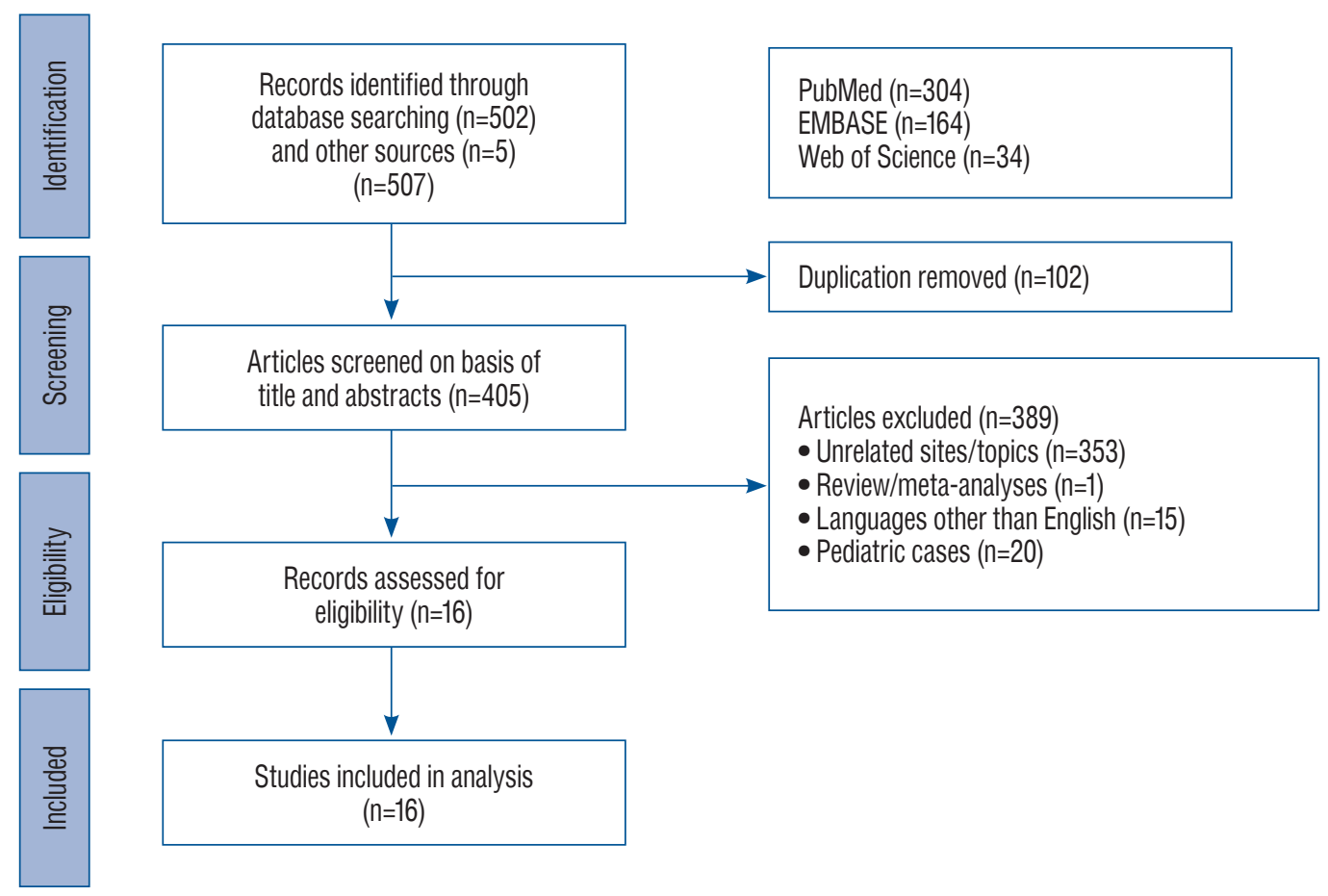

Fig. 1. Flow chart of the literature review process. 
the reference list of the identified articles. One hundred and two duplicate articles were removed. Review of the abstracts and titles led to the exclusion of 389 articles (353 unrelated topics, one review or meta-analysis, 20 pediatric cases, and 15 articles not written in English). Finally, 16 articles were deemed suitable for our literature analysis. We extracted the demographic features, clinical findings, and treatment outcomes from each study. We added two cases from our institute. In total, 18 cases were included in our study.

\section{Case illustration}

\section{Case 1}

A 50-year-old male patient had syncope 16 years ago. Magnetic resonance imaging (MRI) performed at another hospital showed a cystic and non-enhancing mass lesion at the quadri- geminal cistern. It contained a focal calcified nodule (Fig. 2A). Regular follow-up was conducted for 16 years in the outpatient clinic. He had progressive headache 1 year ago. Followup MRI revealed that the cystic mass had increased in size and calcification had changed to dense as well as newly developed enhancing portion which was not shown in initial MRI (Fig. $2 \mathrm{~B})$. The preoperative diagnosis was low-grade tumor such as pilocytic astrocytoma, ganglioglioma, or oligodendroglioma. Surgical resection was recommended. On admission to our hospital, the patient was asymptomatic. Neurological examination including cerebellar function, hearing, and extraocular movement tests revealed normal findings. The tumor was resected through an occipital transtentorial approach. Intraoperatively, the cystic portion was punctured, and the greenish material was drained. The tumor and the calcified structure showed broad adherence to the midbrain and vascular struc-

(A)
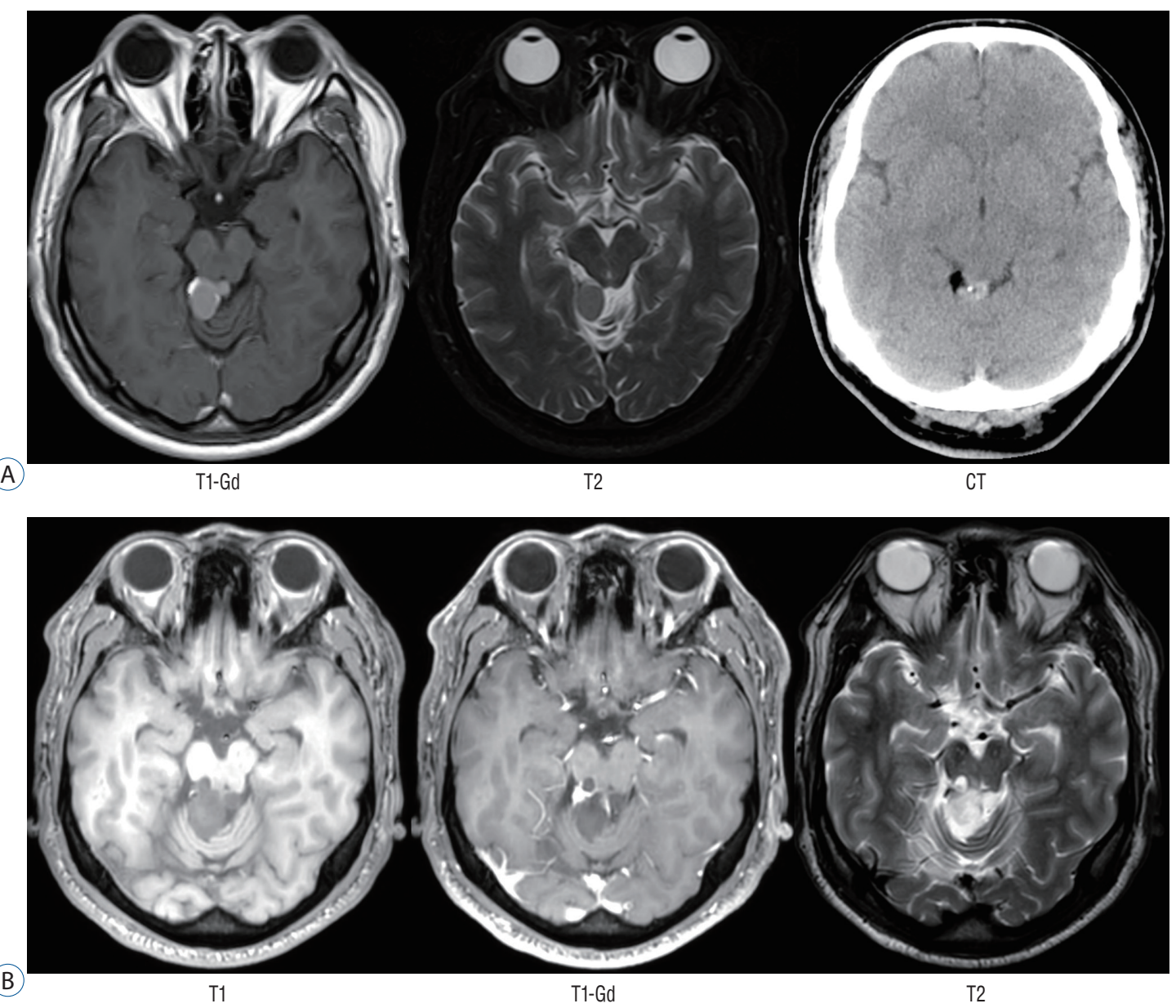

T2

Fig. 2. A : Initial radiographic image showing an oval mass with a heterogeneous signal on T1- and T2-weighted imaging at quadrigeminal cistern. Computed tomography showing focal calcification and lipid component. B : After a 16-year follow-up period, the mass had increased in size and nodular strong enhancement appeared. Gd : gadolinium, CT : computed tomography. 

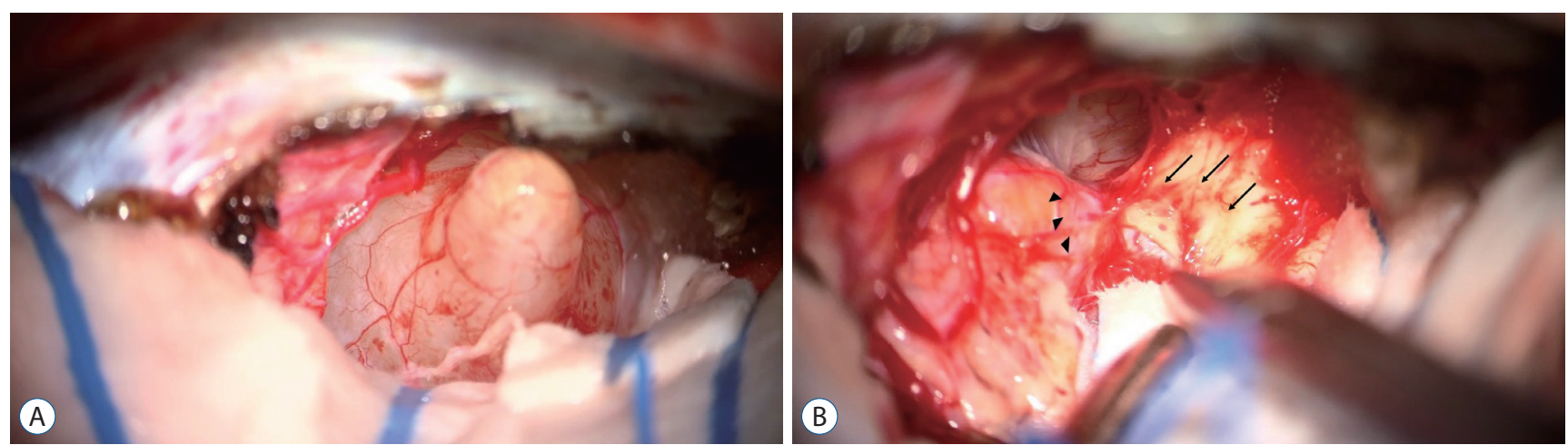

Fig. 3. A : Microscopic view through the occipital transtentorial approach. The tentorium was coagulated and cut. The mass was soft, fragile, and capsulated. B : Severe adhesion was noted between the quadrigeminal plate (black arrows) and the mass (arrowheads). Numerous small vessels were surrounding the mass.

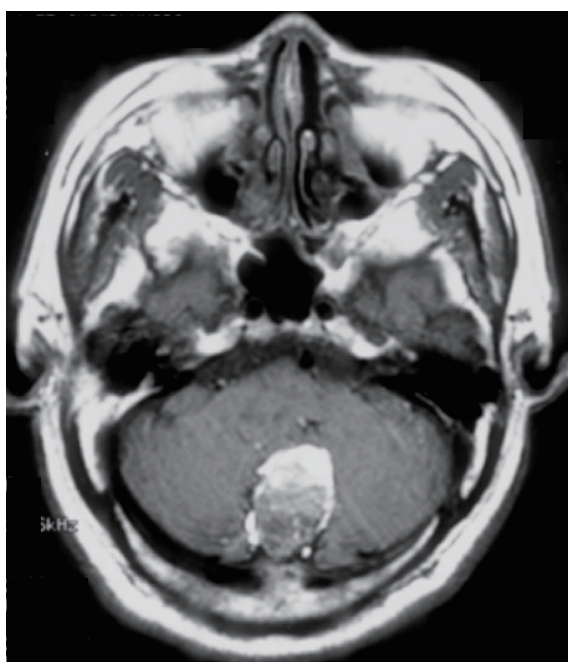

$\mathrm{T} 1$

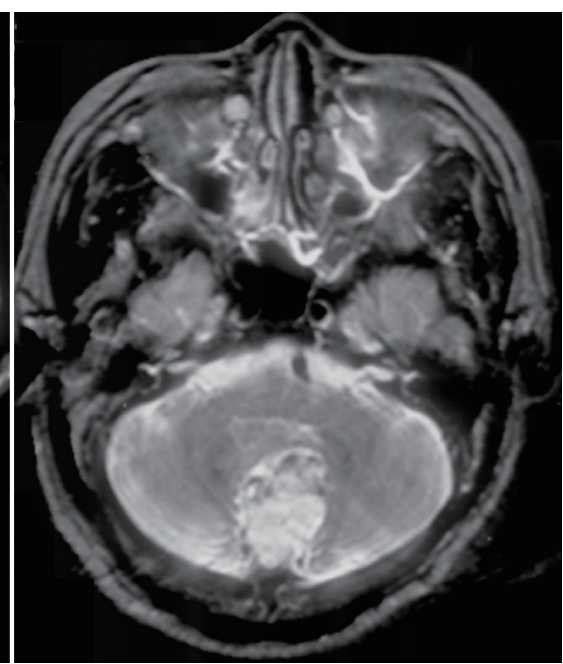

T2

Fig. 4. Image of the mass located at the posterior cerebellum (midline). The image shows heterogeneous signal intensity without peritumoral edema.

tures (Fig. 3). Due to the possibility of injury to the quadrigeminal plate, partial resection was achieved. The patient had dizziness and diplopia postoperatively. Postoperative computed tomography (CT) and MRI revealed high signal intensity at the quadrigeminal plate on T2-weighted imaging.

\section{Case 2}

A 60-year-old male patient had dysarthria and left-sided weakness 2 weeks ago. Initial brain MRI showed multifocal cerebral infarction and posterior fossa tumor at the midline (Fig. 4). The tumor had a high signal intensity on T1-weighted imaging and heterogeneous high signal intensity on T2weighted imaging. Preoperative diagnosis based on radiographic findings was rupture of the dermoid cyst. The patient underwent removal via suboccipital craniectomy. The tumor was totally removed. It contained multiple fragments of hair, sebaceous material, and fibrous tissue. The histological diagnosis was mature cystic teratoma.

\section{Pathologic findings}

Due to expiration for the medical records of the case $2 \mathrm{pa}-$ tient, we reviewed pathologic slide only in the case 1 patient. The tumor sample measured $1.3 \mathrm{~cm}$ in the largest dimension. It was firm and had calcification. The histopathological feature of the entire surgical specimen revealed a tumor with fully differentiated three germ-layer derivates (ectodermal, mesodermal, and endodermal) including the ciliated columnar epithelium, skin appendages, hair follicle, and adipose tissue. The tumor was identified as mature cystic teratoma (Fig. 5). 

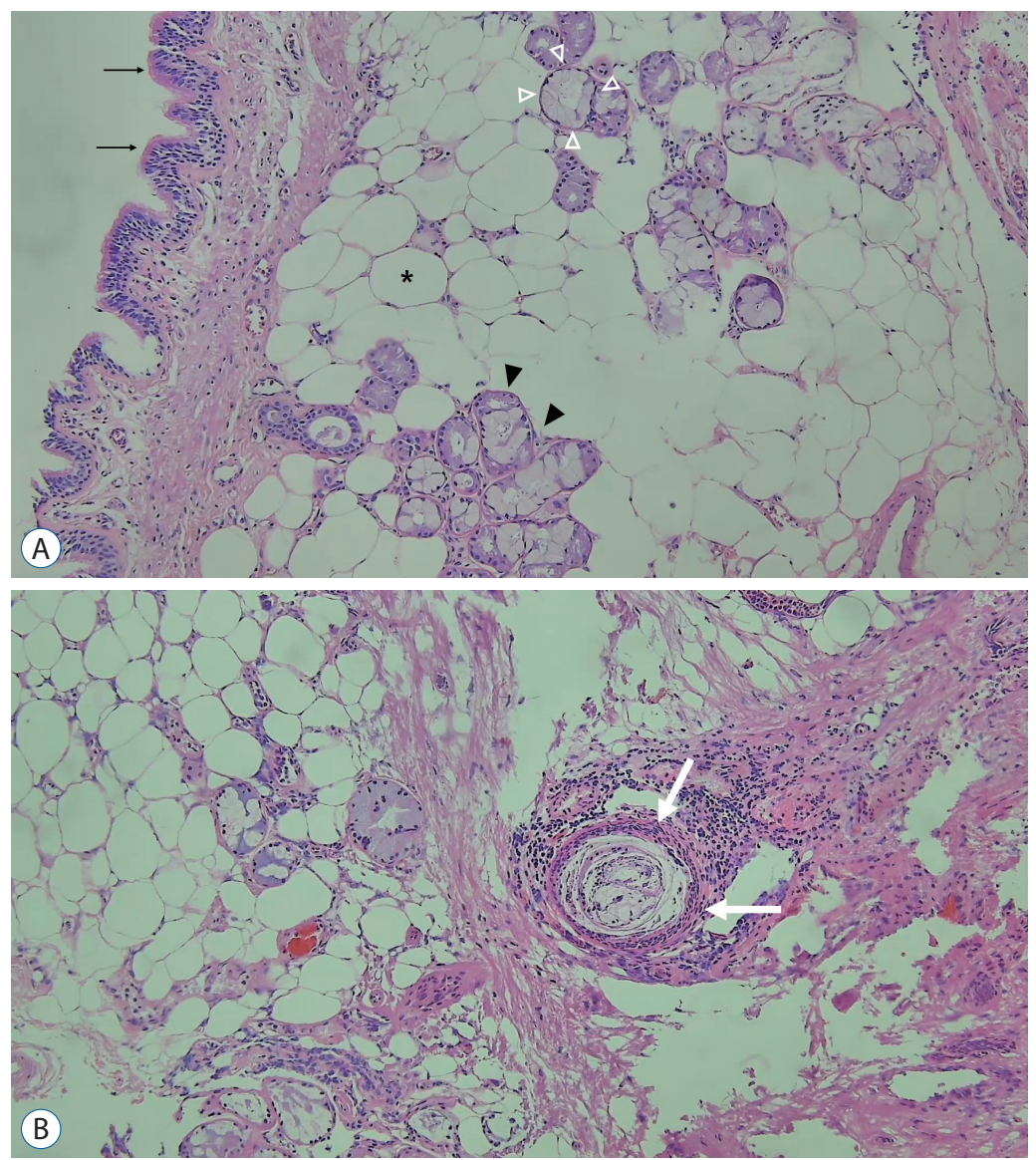

Fig. 5. A : The ciliated columnar epithelium (black arrows), adipose tissue (asterisk), and salivary gland tissue (white and black arrowheads) are observed. The salivary gland tissue shows serous acini (black arrowheads) and mucinous acini (white arrowheads) (H\&E stain, $\times 100$ ). B : A tumor with fully differentiated three germ-layer derivates-the hair follicle (white arrows), adipose tissue, and skin appendages (H\&E stain, $\times 100$ ).

\section{Systematic review}

A total of 16 cases have been reported from 1960 to date, and we added two cases from our institution. Data on patient characteristics, clinical presentation, radiologic features, type of surgery, pathological results, and clinical outcome were analyzed (Table 1).

Of the 18 cases pertaining to posterior fossa mature teratomas, Male to female ratio was $1: 1$. The mean patient age was 47.4 years (range, 19-70). Headache was the most common symptom (10 patients, 55.6\%), followed by nausea and vomiting (nine patients, 50\%). Three patients (16.7\%) had gait disturbance. Radiographic findings varied among patients. Thirteen patients $(72.2 \%)$ had tumors at the midline location, whereas two and three patients had tumors located in the left and right sides, respectively. Calcification was identified in five patients. The angiogram was negative in two cases. MRI signals varied in T1-weighted imaging and gadolinium enhancement, but they were mostly high signal intensity in T2weighted imaging. All patients underwent surgical resection as initial treatment, and most of papers reported no recur- rence after resection. Pathologic diagnosis was benign or mature teratomas in 16 patients (88.9\%), malignant teratoma in one patient (5.8\%), and immature teratoma in one patient (5.8\%). Adjuvant treatment was not performed in all cases.

\section{DISCUSSION}

Germ cell tumors (GCTs) usually originate from the misplacement of embryonal tissues. GCTs comprise germinomas, teratomas, choriocarcinomas, embryonal carcinoma, and endodermal sinus tumor ${ }^{11,12)}$. Teratomas account for $18 \%$ of all GCTs. Jennings et al. ${ }^{11)}$ have reported male predominance (52 : 18) in intracranial teratomas. In our study, the occurrence of posterior fossa teratomas was almost similar in both sexes. Maximal safe resection is curative for intracranial mature teratomas ${ }^{2,9,12,17)}$. The effect of adjuvant chemotherapy or radiotherapy is controversial ${ }^{14,17)}$. Most previous reports showed gross total or subtotal resection. Harada et al. ${ }^{10)}$ reported a fourth ventricle mature teratoma in a 62 -year-old male patient. The 


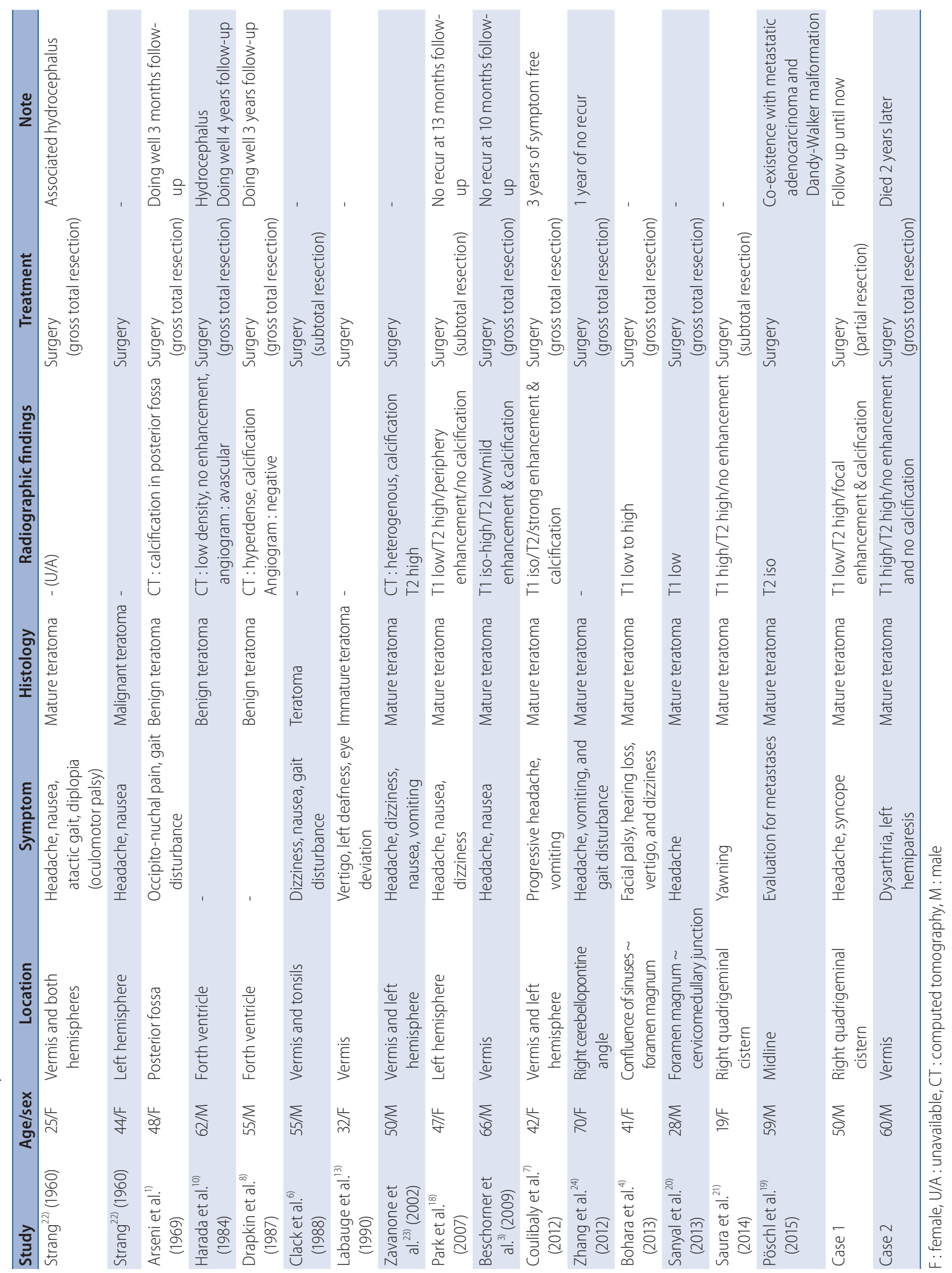


patient underwent gross total resection, and the tumor did not recur for 4 years. The 10 -year survival rates of patients with mature teratoma and malignant teratoma were $92.9 \%$ and $70.7 \%$, respectively ${ }^{16)}$. If gross total resection was not achieved, then the relapse rate was found to increase to $39 \%{ }^{3)}$.

The occurrence of mature teratomas in the posterior fossa during adulthood is exceptionally rare. Our literature search only identified 16 previously reported cases. Posterior fossa teratomas located in the midline in approximately $72.2 \%$ patients, and they have various radiographic findings owing to its heterogeneous components ${ }^{16)}$. Teratomas are misdiagnosed as low-grade tumors or other GCTs. In our case, a 50-year old man was followed up for 16 years. The initial diagnosis was pilocytic astrocytoma based on the findings of a posterior fossa cystic mass in young adults with focal nodular enhancement. However, after 16 years, the cystic mass increased in size, and the calcification became dense. They had common radiographic findings such as slow growing, mural node, and cystic mass. If surgical resection was not performed, then accurate diagnosis would not have been achieved. Bohara et al. ${ }^{4)}$ reported that a 41-year-old female patient had a posterior fossa mass suggestive of a dermoid cyst because the mass was hypodense on CT and involved the sinus tract in the occipital bone. Surgical resection was performed, and the pathologic confirmation was mature teratomas ${ }^{4}$. Coulibaly et al. ${ }^{7}$ also reported a strong contrast-enhancing mass with dense calcification in the posterior fossa. It was diagnosed as meningioma preoperatively according to radiographic findings. A variety of radiographic features in teratomas due to heterogeneous components lead to misdiagnosis, followed by inappropriate treatment such as observation or radiotherapy. Due to the rarity of teratomas, it is difficult to consider teratomas in the initial differential diagnosis. In addition, Liu et al. ${ }^{15)}$ reported that seven of nine mature teratomas showed no contrast or mild contrast enhancement in the cyst wall, and the remaining two teratomas had moderate and heterogeneous enhancement in the solid portion. In contrast, malignant or immature teratomas showed intratumoral nodular enhancement. Additionally, they found that serum alpha-fetoprotein (AFP) levels were elevated in malignant teratomas, whereas the levels in mature teratomas were within the normal range ${ }^{15)}$. Matsutani et al. ${ }^{16)}$ revealed that AFP or human choriogenic gonadotropin was not found in mature teratomas, whereas its level was elevated in immature or malignant teratomas. Kyritsis ${ }^{12)}$ also reported that carcinoembryonic antigen were positive in teratomas.

Spinal cord metastasis occurs in $10 \%$ of all intracranial GCTs. The incidence is higher for germinomas (10\%), endodermal sinus tumors (23\%), males (11\%), and tumors in the pineal gland ${ }^{11}$. Goyal et al. ${ }^{9}$ reported that 23 of 43 cases of central nervous system teratomas were located in the spinal cord. In our study, teratomas in the posterior fossa did not show cerebrospinal fluid seeding to the spinal cord.

The definitive diagnosis of intracranial teratoma can be made histologically. It is difficult to diagnose teratomas using radiological examination only. The heterogenous radiographic findings of intracranial teratoma often lead to misdiagnosis, such as lipoma, dermoid cysts, other GCTs, or craniopharyngiomas, especially in cases of suprasellar lesions. One of our cases was initially diagnosed as a low-grade glial tumor. Most previous cases showed various features and clinical findings. It is occasionally difficult to obtain tissue from tumors located in the posterior fossa because of its complex neurovascular anatomy (brainstem, cranial nerves, and critical vessels). However, whenever feasible, we should perform a craniotomy to ensure an appropriate diagnosis.

This study had several limitations. Because of its small number of patients, a statistical analysis was not performed. As a few cases were quoted from the papers written before 2000 , it was difficult to obtain information about the patients or even the original articles.

\section{CONCLUSION}

The occurrence of mature teratomas located at the posterior fossa in adult patients are extremely rare. Only 16 cases have been reported thus far in the literature. Teratomas can show heterogeneous radiographic findings; hence, we should consider teratomas in the differential diagnosis. If it is possible, maximal safe resection and histological diagnosis are recommended.

\section{CONFLICTS OF INTEREST}

Sang Woo Song has been editorial board of JKNS since November 2014. He was not involved in the review process of this original article. No potential conflict of interest relevant to this article was reported. 


\section{INFORMED CONSENT}

This type of study does not require informed consent.

\section{AUTHOR CONTRIBUTIONS}

\author{
Conceptualization : JHK \\ Data curation : DWS, YHK \\ Formal analysis: DWS, SWS \\ Funding acquisition : $\mathrm{SHH}$ \\ Methodology : JHK \\ Project administration : YHC \\ Visualization : DWS, SJN \\ Writing - original draft : DWS \\ Writing - review \& editing: JHK
}

\section{ORCID}

Dong-Won Shin https://orcid.org/0000-0002-8163-3357

Jeong Hoon Kim https://orcid.org/0000-0001-7385-2368

Sang Woo Song https://orcid.org/0000-0002-5523-3798

Young-Hoon Kim https://orcid.org/0000-0002-8852-6503

Young Hyun Cho https://orcid.org/0000-0002-3274-5096

Seok Ho Hong https://orcid.org/0000-0003-4349-7021

Soo Jeong Nam ～https://orcid.org/0000-0001-9376-359X

\section{References}

1. Arseni C, Dănăilă L, Nicola N, Georgian M, Istrati C : Intracranial teratomas. Acta Neurochir (Wien) 20 : 37-51, 1969

2. Barkley AS, Kuo CH, Leary SES, Ojemann JG, Susarla SM : Unusual radiographic presentation of intracranial mature teratoma and resection via supraorbital approach. World Neurosurg 122 : 81-84, 2019

3. Beschorner R, Schittenhelm J, Bueltmann E, Ritz R, Meyermann R, Mittelbronn $\mathrm{M}$ : Mature cerebellar teratoma in adulthood. Neuropathology 29 : 176-180, 2009

4. Bohara $\mathrm{M}$, Yonezawa $\mathrm{H}$, Karki P, Bakhtiar Y, Hirano H, Kitazono I, et al. Mature posterior fossa teratoma mimicking dermoid cyst. Brain Tumor Pathol 30 : 262-265, 2013

5. Buetow PC, Smirniotopoulos JG, Done S : Congenital brain tumors: a review of 45 cases. AJNR Am J Neuroradiol 11 : 793-799, 1990

6. Clack TD, McGillicuddy JE, Wolf GT : Labyrinthine functional tests and a case of midline cerebellar teratoma. Am J Otol 9 : 481-488, 1988

7. Coulibaly O, El Kacemi I, Fatemi N, Gana R, Saïdi A, Maaqili R, et al. : Mature posterior fossa teratoma mimicking infratentorial meningioma: a case report. Neurochirurgie $58:$ 40-43, 2012

8. Drapkin AJ, Rose WS, Pellmar MB : Mature teratoma in the fourth ventricle of an adult: case report and review of the literature. Neurosurgery 21 : 404-410, 1987

9. Goyal N, Kakkar A, Singh PK, Sharma MC, Chandra PS, Mahapatra AK, et al. : Intracranial teratomas in children: a clinicopathological study. Childs Nerv Syst 29 : 2035-2042, 2013

10. Harada K, Okamoto H, Fujioka Y, Kiya K, Mukada K, Uozumi T, et al. : Teratoma in the fourth ventricle of an elderly adult--case report. Neurol Med Chir (Tokyo) 24 : 499-503, 1984

11. Jennings MT, Gelman R, Hochberg F : Intracranial germ-cell tumors: natural history and pathogenesis. J Neurosurg 63 : 155-167, 1985

12. Kyritsis AP : Management of primary intracranial germ cell tumors. J Neurooncol 96 : 143-149, 2010

13. Labauge $R$, Pagès $M$, Pagès $A$, Ségnarbieux $F$ : Cerebellar teratoma in adults. Contribution of $\mathrm{x}$-ray computed tomography and magnetic resonance imaging. Rev Neurol (Paris) $146:$ 310-312, 1990

14. Lee YH, Park EK, Park YS, Shim KW, Choi JU, Kim DS : Treatment and outcomes of primary intracranial teratoma. Childs Nerv Syst 25 : 1581-1587, 2009

15. Liu Z, Lv X, Wang W, An J, Duan F, Feng $X$, et al. : Imaging characteristics of primary intracranial teratoma. Acta Radiol 55 : 874-881, 2014

16. Matsutani M, Sano K, Takakura K, Fujimaki T, Nakamura O, Funata N, et al. : Primary intracranial germ cell tumors: a clinical analysis of 153 histologically verified cases. J Neurosurg 86 : 446-455, 1997

17. Noudel $R$, Vinchon $M$, Dhellemmes $P$, Litré $C F$, Rousseaux $P$ : Intracranial teratomas in children: the role and timing of surgical removal. J Neurosurg Pediatr 2 : 331-338, 2008

18. Park KB, Park HS, Lee Jl, Suh YL : Mature teratoma in the cerebellar hemisphere of an adult. J Korean Neurosurg Soc 41 : 180-181, 2007

19. Pöschl J, Berger F, Kretzschmar H, Schüller U : A 59-year-old man with two cerebellar lesions and disturbed cerebellar morphology. Brain Pathol 25 : 790-791, 2015

20. Sanyal P, Barui S, Mathur S, Basak U : A case of mature cystic teratoma arising from the fourth ventricle. Case Rep Pathol 2013 : 702424, 2013

21. Saura H, Beppu T, Matsuura H, Asahi S, Uesugi N, Sasaki M, et al. : Intractable yawning associated with mature teratoma of the supramedial cerebellum. J Neurosurg 121 : 387-389, 2014

22. Strang RR : Teratomas of the posterior cranial fossa. ZentralbI Neurochir $20: 359-372,1960$

23. Zavanone M, Alimehmeti R, Campanella R, Ram-Pini P, Locatelli M, Egidi $M$, et al. : Cerebellar mature teratoma in adulthood. J Neurosurg Sci 46 : 35-38; discussion 38, 2002

24. Zhang $S$, Wang $X$, Liu $X$, Hui $X$ : Mature teratoma in cerebellopontine angle in a 70 -year-old female: a rare tumor with exceptional location, age, and presentation. Neurol India 60 : 660-661, 2012 